\title{
UNIVERSITY of DERBY
}

\section{One way or another? Criminal investigators' beliefs regarding the disclosure of evidence in interviews with suspects in England and Wales}

\begin{tabular}{|c|c|}
\hline Item type & Article \\
\hline Authors & Walsh, Dave; Milne, Becky; Bull, Ray \\
\hline Citation & $\begin{array}{l}\text { Walsh, D. et al (2015) 'One Way or Another? Criminal } \\
\text { Investigators' Beliefs Regarding the Disclosure of } \\
\text { Evidence in Interviews with Suspects in England and } \\
\text { Wales', Journal of Police and Criminal Psychology, } 31 \\
\text { (2):127 }\end{array}$ \\
\hline DOI & $10.1007 / \mathrm{s} 11896-015-9174-5$ \\
\hline Publisher & Springer \\
\hline Journal & Journal of Police and Criminal Psychology \\
\hline Rights & $\begin{array}{l}\text { An error occurred on the license name. } \\
\text { Archived with thanks to Journal of Police and Criminal } \\
\text { Psychology }\end{array}$ \\
\hline Downloaded & 19-Mar-2018 15:48:38 \\
\hline Link to item & http://hdl.handle.net/10545/621081 \\
\hline
\end{tabular}




\section{One way or another? Criminal investigators' beliefs regarding the disclosure of evidence in interviews with suspects.}

\section{Introduction}

During the 1990s a model for the interviewing of suspects was implemented in England and Wales, called the PEACE framework (see Milne \& Bull, 1999; Shepherd \& Griffiths, 2013, for a comprehensive description). Since its introduction, there have been several studies examining real-life investigative interviews that have been conducted in those countries (e.g. Bull \& Soukara, 2010; Clarke \& Milne, 2001; Griffiths \& Mine, 2006; Leahy-Harland, 2012; Oxburgh \& Ost, 2011; Oxburgh, Ost, \& Williamson, 2006; Soukara, Bull, Turner, Vrij, \& Cherryman, 2009; Walsh \& Bull, 2010a, 2010b; 2012a, 2012b; Walsh \& Milne, 2008). A common finding of these studies is that the unethical practices found in earlier studies of police practice in these countries, when questioning suspects (see Irving, 1980), have all but disappeared. However, while many of those studies cited above still find aspects of investigative interviewing requiring improvement (such as rapport skills, questioning, summarising and theme development), a research base to establish what exemplars of best practice are still remains too sparse (Bull, 2013). The present study aims to learn of practitioner beliefs in England and Wales as to a key area of the investigative interviewing of suspects; the disclosing of evidence in interviews.

\section{Evidence disclosure in interviews}

From research that has been conducted across the world the disclosing of evidence to suspects has been found to be an important feature in either (i) eliciting confessions (Cassell \& Hayman, 1996; Gudjonsson \& Petursson, 1991; Kebbell, 
Hurren, \& Roberts, 2006; Moston, Stephenson, \& Williamson, 1992; Sellers \& Kebbell, 2009; Soukara et al., 2009; Walsh \& Bull, 2012a); (ii) detecting deception (Dando, Bull, Ormerod, \& Sandham, in press; Granhag, Strömwall, Willén, \& Hartwig, 2012; Hartwig, Granhag, Strömwall, \& Kronkvist, 2006; Hartwig, Granhag, Strömwall, \& Vrij, 2005; McDougall \& Bull, in press; Sorochinski et al., in press); or (iii) obtaining further evidence and/or accurate, complete, and reliable accounts (Nystedt, Nielsen, \& Kleffner, 2011; van der Sleen, 2009; Walsh \& Bull, in press).

Prior studies have found that suspects are more likely to admit their wrongdoing when they perceive the evidence as strong (Baldwin, 1993; Moston et al., 1992). Smith, Bull, \& Holliday (2011) found that lay people are frequently inaccurate when assessing evidence strength, often overstating its probative worth. While this finding suggests that interviewer skills do not mediate interview outcomes, Walsh and Bull (2012a) found that evidence weight alone would be an unreliable factor in persuading suspects to confess. They found that frequently skilled displays of ethical, non-judgemental, and non-aggressive attitudes were also influential in this regard (see also Holmberg \& Christianson, 2002; Kebbell, Alison, \& Hurren, 2006; Kebbell, Alison, Hurren, \& Mazzerole, 2010).

Soukara, Bull, and Vrij (2002) found that when interviewers believe they hold strong evidence they admit to undertaking less preparation ahead of the interview, although it has been found that they tend to ask more open questions (Häkkänen, Ask, Kebbell, Alison, \& Granhag, 2009). Whether investigators" judgements concerning evidence strength are accurate has been considered by Smith and Bull (in press), finding that police officers reported that they had received little or no training in how to interpret/assess forensic information. In their study, respondents tended to correctly discriminate differences between weak and strong evidence. 
However, these assessments tended to gravitate towards the scale's centre ground used in that study, even when officers were tested with evidence examples that were exceptionally strong or weak in their probative value. Such tentativeness in assessment of the evidence may explain why these police officers reported that their lack of understanding as to its actual strength affected how they undertook to reveal that evidence, in terms of its timing during an interview (Bull, 2014).

\section{Evidence disclosure strategies}

Concerning the matter of the timing of evidence disclosure in interviews, the cited studies do not advocate a single approach but essentially in one of three ways (that is, either early, gradually, or late). Bull (2014) provides a more detailed explanation of each of these evidence disclosure mode (EDM) strategies. In brief 'early' refers to evidence being disclosed at the start of the interview, before questions have been put to the suspect (see Moston et al., 1992; Sellers \& Kebbell, 2009; Leo, 1996). 'Gradual' evidence disclosure involves a phased presentation of information/evidence, provided in a 'drip-feed' effect throughout the interview (Dando \& Bull, 2011; Granhag et al., 2012). In contrast, 'late' disclosure relates to the gathering of the whole story from the suspect, and dealing with all potential alibis and the like, before presenting the evidence (see Hartwig et al., 2005; 2006, Sorochinski et al., in press).

In a recent study, conducted in Taiwan, police officers reported that they typically disclosed evidence early in the interview (Tsan-Chang Lin \& Chih-Hung Shih, 2013). Such an approach is one often believed to be employed in interviews conducted in the USA, since suspects there have a right to know before questioning what evidence the police hold, which might incriminate them (De Paulo \& Bond, 
2012). However, it may not always be clear until an account is provided whether the information held is of any probative value, since an explanation might be provided by the suspect, in this initial account, that suggests that the information is not incriminating (Bull, 2014). Moreover, early disclosure of evidence might lead some suspects (particularly vulnerable ones - see Gudjonsson, 2003) to adapt their subsequent accounts to include the information/evidence given earlier, thus providing a distorted portrayal of events, and even a false confession (sometimes purposely). For other suspects, knowledge of what evidence the police possess may allow them to create a false account of events that incorporates this information (Read, Powell, Kebbell, \& Milne, 2009). Such contamination might possibly be avoided when information is either wholly or largely withheld until after an account has been provided by the suspect. Further, Walsh and Bull (in press) found in their field study of PEACE-trained investigators in England that officers using 'early' disclosure approaches were very rarely found to be skilled, and even more rarely gained the PEACE framework's main objective of gathering a comprehensive and reliable account.

In Bull and Soukara's (2010) study of real-life interviews conducted by police officers in England, information/evidence was found to be revealed gradually. It was also found that more often than not evidence was being disclosed either at the time, or shortly before, a confession was made by suspects, who had initially denied offending. However, it is also true that in their earlier study such 'gradual' evidence disclosure was also evident in interviews with suspects who continued to deny any wrongdoing (Soukara et al., 2009). Furthermore, Walsh and Bull (in press) found that a particular form of 'gradual' evidence disclosure (labelling it 'deferred gradual') was optimal in terms of gathering a fulsome account, tested robustly for its plausibility 
(that is, releasing the evidence in stages, but only after each sub-topic within interviews had been thoroughly covered by way of gathering an initial account, followed by a series of probing questions, designed to elicit much finer details).

Using a rating scale to measure interviewing skill levels, they also found that another form of 'gradual' evidence disclosure (where challenges were made of suspects, before any or much attempt to elicit the finer details had been made, which they described as the 'reactive gradual' evidence disclosure mode) was much less skilful, and less likely to obtain a comprehensive account than 'deferred gradual' evidence disclosure strategies. Walsh and Bull also found that 'deferred gradual' evidence disclosure was found to be more skilled, when compared to 'late' evidence disclosure interviews (although 'late' disclosure was assessed, in turn, as more skilful than the 'early' or 'reactive gradual' approaches, found to be the least skilled approaches and the ones least likely to yield a comprehensive account). However, they further found that 'late' disclosure interviews did not always gain a comprehensive account. Alongside Fahsing (2014), Walsh and Bull expressed concern at investigators' frequent failure to cover all the alibis and the like in their preceding questioning strategy before putting evidence to suspects; a fundamental requirement of the 'late' evidence disclosure model.

'Deferred gradual' disclosure, on the other hand, may (i) lessen the chances of suspects providing no responses to questions (Bull \& Soukara, 2010); (ii) uncover lies (Dando et al., in press); and (when used skilfully) (iii) more likely gain either a comprehensive and reliable account or a reliable confession (Walsh \& Bull, 2010b; 2012a; in press). Indeed, the PEACE framework prescribes just such an approach. On the other hand, Granhag, Hartwig, Mac Giolla, \& Clemens, (2015) argue that gradual disclosure strategies may well in time be overcome by those resistant 
suspects who repeatedly experience police interviews. Further, Sorochinski et al. (in press) speculatively posit whether evidence, when disclosed in an incremental manner, may lead subtly to passive compliance from the suspect, and in turn, in worst case scenarios, even prompt false confessions from suspects. However, in their study, the mock interviewers, in those interviews where evidence was released gradually, employed a strategy considerably more resonant with 'reactive gradual' than 'deferred gradual' information/evidence disclosures.

Whether a 'late' approach is actually feasible in interviews with many or several pieces of complex information/ evidence remains unclear, as the pioneering experimental studies conducted by Hartwig and her associates were typified by less complex crime scenarios (but see Sorochinski et al., in press, who found 'late' disclosure to be effective in uncovering liars when using a more detailed paradigm). On the other hand, Jordan et al. (2012) found no significant difference in the rate of detecting deception between interviews where evidence was presented either 'early' or 'late' (likewise for confession rates in their study too).

The use of simpler crime scenarios is also a concern when examining experimental research concerning other evidence disclosure strategies. For example, Granhag et al.'s study (2012) involved an uncomplicated theft scenario when examining the effectiveness of 'gradual' disclosure (which these researchers termed 'incremental'). Interestingly, however, they also utilised as part of their study an 'Evidence Framing Matrix', finding that when information relating to the evidence was gradually released in order of its strength (beginning with the least strong first), deception was more frequently identified. Dando et al. (in press), using a more complex methodology concerning terrorist activity undertaken in their laboratory based study, also found that a 'gradual' approach was much more likely to identify 
both liars and truth-tellers. This was particularly the case when trained investigators conducted the interviews.

The foregoing reflects the agreed importance concerning evidence disclosure in interviews (though it remains contested as to whether one strategy is more effective than another). It also remains unknown whether a unitary approach to disclosing evidence is universally appropriate, or whether other strategies are more suitable, when considering, for example different offences, evidence strength, or even suspects' personalities (or their responses to questioning). Walsh and Bull (2010a) found no single strategy apparent in their British field study in regard to one of these three methods. Further, concerning what Granhag and Hartwig (2015) refer to as evidence framing (e.g. evidence tactically revealed in a chronological order, strongest first, weakest first etc.), neither did Walsh and Bull (2010a; in press) find a solitary approach evident in their field study.

In light of the competing views the present study involved a survey, undertaken of serving investigation professionals in England and Wales, to seek their beliefs as to which method they believe they undertake (and their reasons for their choice). Considering the influence evidence disclosure has on affecting the outcome of interviews with suspects (and the training these investigators are likely to have received, which emphasises the undertaking of gradual revelations) it was hypothesised that respondents would opt for a phased approach and that their reasoning would focus upon the gathering of fulsome and reliable accounts, reflecting the principles of the PEACE framework. It was also hypothesised that no single viewpoint would emerge concerning the framing of various items of evidence. 


\section{Methods}

\section{Materials}

In the present study a questionnaire was designed (see Appendix 1) that initially asked for certain demographic information relating to (i) length of service; (ii) whether or not they had received either basic or advanced training in the PEACE framework; and; (iii) the type of investigations they conducted. Questions then followed that concerned the type of planned information/evidence disclosure tactic they preferred,

Choices given were based on the extant literature that is dominated by the three approaches (early, late or gradual disclosure). It was also asked whether they actually carried out any prepared strategy, and if they changed from that which they had planned to undertake, what prompted such changes. Questions were also asked as to how sure they were of the suspect's guilt prior to an interview, and whether this attitude influenced their choice of tactic.

Survey participants were also asked about the order in which they disclosed items of evidence, such as increasing evidence weight, incident chronology, or a strategy that was felt (in their view) to be 'logical'. Open ended questions also sought explanations from participants for their given answers to for their reasoning for (i) their chosen strategy; (ii) any lack of adherence to their planned strategy; (iii) any revised plan; (iii) their rejection of other strategies; and (iv) any presumptions of guilt. If their answer to the questions relating to chosen strategy, or the manner in which gradual evidence was disclosed, suggested a contingency upon contextual factors further open-ended questions were asked of participants to establish what these were dependent upon.

\section{Procedure}


Having received ethical approval for the study from the first author's University, he undertook a series of face to face presentation sessions to a range of serving professionals between September 2012 and May 2013, who were employed in various parts of England and Wales either as police officers or as civilian investigators (the latter group being employed either by government departments, such as income tax/social security benefit fraud investigators, or in the private sector in the role, say, of investigating insurance frauds). Before undertaking these sessions the first author asked the participants to complete the questionnaire. They were advised not to look at their neighbours' questionnaire, and being supervised by the first author, it was ensured that the questionnaires were completed independently. Additionally, the first author used the assistance of a serving police officer, who distributed the questionnaire to fifteen of his colleagues in Wales. Again, those involved were advised that these questionnaires should be completed autonomously by respondents. Once completed, these questionnaires were returned by the conduit to the first author. This method was replicated for eight further questionnaires, where an investigations manager recruited participants, using his contacts in the fraud/financial crime investigation arena.

General details of the sample.

A total of 266 questionnaires were issued, from which 224 were returned (a response rate of $84 \%)$. Table 1 shows that $58 \%$ of respondents $(n=130)$ were from investigators with over 10 years' professional investigative experience, while another $26 \%(n=59)$ had undertaken their investigative role for between five and ten years. $88 \%$ of respondents had undergone training in the PEACE framework, while $60 \%$ of respondents stated that they had undergone further or advanced training. Thirty- 
three percent $(N=74)$ of the respondents were benefit fraud investigators, $30 \%$ $(n=67)$ were volume crime police officers, and $29 \%(n=65)$ were either internal fraud investigators or tax, insurance, or trade fraud crimes investigators. The residual $8 \%$ of respondents $(n=18)$ were police officers who investigated most serious crimes (e.g., murder, sex offences, or terrorism). Table 1 portrays that over half of those least experienced respondents (i.e., those with three years or less service) were fraud financial crime investigators, while a similar proportion of benefit fraud investigators were among those most experienced of those completing the questionnaire. Ninety-two percent of serious crime investigators $(n=17)$ had more than five years' experience, the largest proportion of experience by function of job role.

INSERT TABLE 1 ABOUT HERE

\section{Results}

Preferred evidence disclosure strategies

As can be seen from Table 2, over two thirds of the 221 respondents, who answered this question (three not doing so), stated that they planned to undertake a gradual evidence disclosure strategy. Using open-ended questions to invite explanations for their beliefs, $70 \%(n=107)$ respondents who said they planned to disclose evidence gradually, stated their planning involved allowing suspects to provide a detailed first account before revealing the information/evidence held (i.e., a 'deferred gradual' approach), whereas the remainder said that they disclosed evidence immediately (i.e., a reactive gradual strategy) either when a conflict arose between any given account and the evidence to hand $(n=26)$, or when denials were received $(n=19)$. 


\section{INSERT TABLE 2 ABOUT HERE}

Ninety-six percent of respondents $(n=215)$ stated that they adhered to their planned strategy either most or all of the time. No respondent stated that they never or rarely undertook their planned strategy. Any changes to planned strategy, when they did occur, were attributed to various causes. These ranged from a suggested flexibility in response to either suspects (i) making admissions or denials $(n=75)$; (ii) providing new/unforeseen revelations or evidence $(n=44)$; (iii) being willing/unwilling to co-operate ( $n=42)$; or (iv) having their lawyer present $(n=3)$. Twenty-six percent of volume crime, benefit fraud and other financial crime/fraud investigators $(n=53)$ conceded that they did change their plan, if only occasionally. On the other hand, without exception, the serious crime investigators said they adhered to their original prepared evidence disclosure strategy.

Twenty-five respondents, however, stated that their planned strategy was dependent upon certain factors, citing (i) suspects' willingness or refusal to cooperate; (ii) the strength of the evidence available, and (to a lesser extent); (iii) offence type or complexity; or (iv) the expected presence of the suspect's lawyer as reasons for their decision-making. However, given that this question pertained to planning ahead of interviews, it remained unclear from their answers as to how they may know at the planning stage whether suspects would be either subsequently compliant or obdurate when being questioned.

When examining responses concerning planned disclosure strategy by function/ job role, Table 3 shows it was found that the majority in each investigative role preferred a 'gradual' disclosure mode strategy (although to a lesser extent, volume crime police officers). Regarding investigative experience, the majority of those (who in the prior 12 months had received training in the PEACE model, which 
recommends the gradual method of evidence disclosure), and those more (and most experienced) believed that they undertook the incremental form of evidence disclosure. Support for this model appeared less so from those with 1-5 years' experience. However, after undertaking one-way analyses, no significant difference was found between the groups' (i.e. length of professional experience or job role) beliefs, both Fs $<0.88$, both $p s>.38$.

\section{INSERT TABLE 3 ABOUT HERE}

Respondents were also encouraged, via open-ended questions, to make several justifications for their chosen strategy. For those, who stated that they would rather undertake to disclose evidence 'early', they commonly justified their choice by saying that this approach would (i) show suspects the strength of the case against them $(n=8)$; (ii) prompt an account $(n=6)$; and (iii) encourage admissions $(n=8)$. Further comments also included that an 'early' evidence disclosure strategy would also expedite the interview process $(n=5)$, and avoid the possibility of suspects remaining silent $(n=4)$. Early evidence disclosure was also reckoned to reduce the opportunity for suspects to think $(n=2)$. The presence of a lawyer was also mooted as a reason for 'early' disclosure $(n=2)$.

Those who reported that they opted for a 'gradual' strategy, offered a rationale that such an incremental approach would assist them in controlling the interview more effectively and be more likely to obtain a fulsome account from suspects ( $n=$ 98), particularly (for 58 respondents) when the case involved (i) complexity; (ii) suspected offences that may have occurred over a period of time; or (iii) many pieces of evidence. Further reasons for preferring a 'gradual' strategy included investigators being better enabled to expose inconsistencies and lies $(n=43)$. As 
such, it was also stated by 17 respondents that in these circumstances challenges could then be more effectively made, while building up the pressure on the suspect so that he/she becomes increasingly aware of the evidence held $(n=35)$. In this way the gradual production of evidence was stated by 55 respondents in the survey as one that, in contrast to the approach of early disclosure, avoided or reduced the possibility of suspects providing a false version of events (that accounted for the already disclosed evidence). Other viewpoints for opting to reveal evidence in a phased manner included allowing time and opportunity for suspects to think who, in turn, would then be better placed to provide a more comprehensive account $(n=71)$. Of those respondents who conducted serious crime investigations, three stated that, because of the often urgent need to make an arrest and interview suspects in these types of offences (often before a full investigation had been allowed to be completed), gradual disclosure was somewhat inevitable. They explained that, in such circumstances, it was only after arrest that further information or evidence may emerge in a more staggered fashion from various sources (such as evidence from forensic tests) and, as such, would then be revealed to suspects similarly.

Those who favoured 'late' disclosure argued their case by stating that this approach enabled lies to be better uncovered by such evidence-withholding strategies $(n=13)$. They reasoned that by asking questions beforehand that would cover all alibis and the like suspects would have no opportunity to provide further ones that could reasonably excuse them from continuing suspicion $(n=9)$. As such, it was suggested that a guilty suspect would in these circumstances be unable to account for any conflicts that arose between his/her provided version of events and the evidence to hand, only being revealed latterly in the interview $(n=11)$. 
It was also examined whether there were any differences in disclosure choice between the civilian investigators in the survey (whose role would be likely more homogeneously defined, reflective of the more narrow nature of their investigative task) and police officers (whose investigations were likely more varied). A $2 \times 4$ Chi square test indicated a significant association between job role and choice of evidence disclosure strategy; $\chi^{2}(4, \mathrm{n}=220)=16.87, p=<.01$, phi $=.28$. While only $6 \%$ of civilian investigators said they used an 'early strategy', $24 \%$ of police officers preferred this approach. Little difference between the two groups of investigators was found when examining other disclosure options (where $72 \%$ of civilian investigators and $65 \%$ of police officers preferred a 'gradual' strategy; $7 \%$ of the former group favoured a 'late strategy compared to $4 \%$ of police officers; and $13 \%$ of non-police investigators inclined towards the view that any strategy was dependent on other factors, while $8 \%$ of police officers suggested likewise).

To shed some light as to why a quarter of police officers in the survey should prefer an 'early' strategy, which is at odds with their training, a further $2 \times 4$ Chi square test was conducted, relating to the disclosure choices made between those 68 volume crime officers and those who investigate serious crime $(n=18)$, finding a significant effect; $\chi^{2}(3, \mathrm{n}=86)=6.52, p=<.01$, phi $=.28$. That is, only $6 \%$ of police officers who investigate serious crime preferred an 'early' strategy, while $29 \%$ of their volume crime counterparts opted for this approach. A 'gradual' strategy was selected by $79 \%$ of serious crime police investigators and by $61 \%$ of volume crime police officers. None of the former group preferred a 'late' disclosure approach, although $17 \%$ of them said their decision was case-dependent. In comparison, $5 \%$ of volume crime police investigators, selected 'late' strategies, while $6 \%$ of them said their choice was influenced either by the type of case, the presence of a lawyer, the 
suspect's responses, or how strong the evidence was perceived by them (i.e. the investigators). Such explanations were also commonly provided by serious crime police investigators and civilian investigators.

Order in which evidence is disclosed

In connection with how the framing of evidence items would be disclosed to suspects (regardless of whether survey respondents preferred an 'early', 'gradual', or late' disclosure strategy) Table 4 shows that the most favoured approach among the 199 respondents (twenty-five abstaining) was found to be that of initially presenting least strong evidence first. However, one in five respondents admitted to having no plan. A further 25 respondents stated that their choice of order was contextually dependent (as with the preferred EDM). Twelve cited reasons, such as, offence sophistication or suspect type, or particular circumstances during the interview. Others were less specific (e.g. Respondent \#36 stated "if the opportunity is right"). Responses were also given that suggested that the order of evidence disclosure was more a reactive measure to what the suspect said. For example, if the suspect willingly made admissions then respondents felt that it was less important to consider the order of disclosure $(n=5)$, whereas resistance would require a more structured approach, with any "conclusive" piece of evidence, generally withheld till the last. In contrast, it was mooted by Respondent \#200, a benefit fraud investigator, that such strong evidence might be introduced first to "more quickly weaken the suspect's resolve".

INSERT TABLE 4 ABOUT HERE 
It is perhaps more important to examine the order in which evidence is disclosed in 'gradual' evidence disclosure strategies than in others since in this approach investigators 'drip-feed' evidence throughout the interview. Further, the vast majority of respondents in the present study stated that they preferred to 'gradually' disclose evidence. It was found that among this particular group of respondents that (as with the entire sample of respondents) disclosing the least strong evidence first was the most popular option. Although proportionately less than the overall sample with fewer than one in five conceded to having no forethought as to the how to disclose pieces of evidence.

\section{Presumption of guilt and evidence disclosure}

As Table 5 shows, of the 216 respondents who revealed their feelings concerning the suspect's guilt before commencing the interview 56\% $(n=120)$, declared that they believed the suspect was guilty either often or very often. Of the respondents' various reasons offered for such beliefs some $(n=75)$ related to the information/evidence to hand that had already been collected during the investigation (including suspects 'being caught in the act'). Other views included guilt being presumed due to the suspect's criminal antecedents or personality $(n=91)$, and any pre-interview utterances made by the suspect that indicated his/her guilt $(n=14)$. $70 \%(n=46)$ of volume crime investigators, $61 \%(n=38)$ of financial crime/other fraud investigators, and $46 \%(n=33)$ of benefit fraud investigators stated that they regularly believed that the suspect was guilty prior to the interview. However, in contrast, just three of the 17 responding serious crime investigators (18\%) professed to have such guilt presumption. Of the 199 respondents who admitted that they believed suspects were guilty at least some of the time before the interview, $43 \%$ ( $n$ 
= 86) acknowledged that it would affect their chosen strategy at least some of time. However, it was found, after undertaking a $2 \times 2$ chi- square test, that there was no significant difference between the tendencies to change/retain EDM strategy (always/sometimes or never), regardless of whether guilt presumption or openmindedness existed; $\chi^{2}(1, \mathrm{n}=216)=0.28, p=.60$, phi $=.04$.

\section{INSERT TABLE 5 ABOUT HERE}

What influences the choice of evidence disclosure strategy?

Standard multiple regression analyses were conducted to assess which, if any, of the particular variables had a stronger association with the respondents stated preferred EDM (see Table 6). Responses were analysed to determine whether any of (i) training in the PEACE model; (ii) advanced training; (iii) investigative experience; (iv) job role; or (v) guilt presumption were more influential regarding preferred evidence disclosure strategy. Table 6 shows that little relationship was found between any of these variables and the stated evidence disclosure choice. Investigator role, was the only variable significantly associated with the chosen EDM, although (as with all the other variables) only with a modest correlation.

INSERT TABLE 6 ABOUT HERE

\section{Discussion}

The PEACE framework, pioneered in England and Wales over twenty years ago, is argued to have contributed (along with the mandatory tape recording of interviews 
with suspects, together with the implementation of legislation in England and Wales) to the consistent absence of unethical tactics, regularly found to be the case in several field studies of conducted interviews with suspects. What remains less certain is how particular tactics and strategies help reinforce the framework in helping meet its central aim; that is, the gaining of a reliable and comprehensive account from interviewees. The present study set out to examine evidence disclosure strategies, consistently found in the extant literature to be influential in achieving such aims, hypothesising that a 'gradual' approach would be dominant in professionals' stated choice.

To the extent that the 'gradual' strategy was found to be preferred by over $2 / 3$ of the respondents the hypothesis was satisfied. This finding, perhaps, should not be wholly surprising since the training investigators receive in England and Wales explicitly advocates this approach. Prior to the introduction of the PEACE framework, Moston, Stephenson, and Williamson (1992) found 'early' disclosure to be commonplace, and (more recently) Tans-Chang Lin and Chih-Hung Shih (2013) found that Taiwanese police officers' (most likely to be untrained in the PEACE model) believed that they undertook an early strategy. In the present study PEACE training also appears to influence reasoning. That is, when justifying their choice of EDM, respondents argued that a 'gradual' approach would allow opportunity for investigators to gather, and for suspects to give, a reliably comprehensive account (being the aims of the PEACE model). Nevertheless, a quarter of respondents, whose choice was a 'gradual strategy', indicated that before carrying out this EDM they would consider such matters as (i) the complexity of the case; (ii) the offences under investigation; (iii) the amount of evidence available, (iv) the suspect; or (v) the 
presence/absence of a lawyer (that is, their final choice of EDM would be influenced by such matters).

It was found in the present study that a 'deferred gradual' evidence disclosure strategy was more likely to be one that investigators said they undertook. It was argued that such an approach, with its integral 'drip-feed' characteristic, may well incrementally and increasingly make suspects aware, as the interview develops, of the amount of information held by investigators (and, where they have not told the truth, make them also aware that their account does reconcile with evidence being gradually revealed). Such an approach, it was speculated, may prompt or encourage suspects to make responses (while arguably making it increasingly difficult for them to either keep silent or continue to provide the same false account), either by their countering the gradually disclosed information that interviewers reveal with utterances that either explain, refute or concede the disclosed information (whether true or false explanations/refutations/ concessions). Such phased responses by suspects, it was claimed, would then be reconciled by interviewers for their plausibility, either against suspects' earlier revelations (not unlike the 'late' disclosure strategy) or against information still being withheld, being planned for 'deferred gradual' disclosure at later stages in interviews.

Twenty-five percent of respondents, however, said that they favoured an 'early' disclosure strategy (arguing that this approach would efficiently reveal to suspects the evidence against them. prompting an early confession). Walsh and Bull (in press) have, however, found that interviews tended to end without obtaining either a confession or a comprehensive account, when 'early' disclosure was conducted. More, Read et al. (2009) caution that some vulnerable suspects may well integrate the revealed evidence in to their accounts, compromising what should be 
the aim of interviews with suspects, i.e., to search for the truth. Respondents in their first three years of experience more often stated that they preferred an 'early' strategy, a finding which might be explained by their being yet to be fully comfortable with the more demanding 'gradual' or 'late' strategies. Preference for 'early' disclosure (for some investigators) may also be a product of their main duties, which due to their inexperience might be expected to generally involve less complex, volume crimes. The present study found that those opting for early disclosure tended to be those police officers investigating volume crime, where the matters that they investigate, due to their regularity, might lead to a rather expeditious (as opposed to efficient) approach to investigation.

Other survey respondents, albeit fewer in number, stated they would choose to undertake 'late' disclosure strategies. 'Late' disclosure, it was argued would likely detect any lies through within-interview inconsistencies. 'Late' disclosure may well be be also viewed as congruent with the principles of the PEACE framework, particularly as the 'late' approach aims to exhaust all potential alibis and the like that could possibly occur before revelation of the evidence held. However, Walsh and Bull's field study (in press) found that such endeavours are unlikely to meet their goals as investigators do not tend to cover all alibis and the like in practice, particularly when the case possesses more complex characteristics. Moreover, a concern with the 'late' approach could be that the continued withholding of information/evidence, while interviewers proceed to conduct questioning, probably at length (that is aimed to cover all possible excuses that a suspect might give), could lead to a lack of co-operation from suspects, though, say, fear or mistrust (Kebbell at al., 2006). Indeed, Granhag and Hartwig concede that the 'late' approach is ineffective if the suspect remains silent when being questioned. On the other hand, 
'late' (and, indeed, 'gradual') approaches might enable the maintaining of rapport - a key element in interviews; see Walsh \& Bull, 2012). 'Gradual' and 'late' approaches continually invite suspects to provide explanations in response to what the interviewer asks or reveals (having first requested him/her to freely give an account). Both approaches include a requirement to probe for micro-details, where inevitable turn-taking will occur between the interviewer's questions and the suspect's provided responses.

Most investigators said that their planned strategy was one they actually carried out. Of course, what investigators say they do, and what they actually do has been found to be different (O'Neill \& Milne, 2014). Whether the level of planning is thorough remains open to conjecture. Several studies have shown that officers admit that they do not always plan, or (when their interviewing practice is examined) they do not always demonstrate preparedness (Clarke \& Milne, 2001; Walsh \& Bull, 2010a; Walsh \& Milne, 2007; 2008). Indeed, the present study, found that one in five respondents acknowledged that they had not thought that much, if at all, about the actual order they disclosed items of information/evidence. However, all serious crime investigators said they planned their evidence framing strategy, consistent with Griffiths' (2008) study of their practice.

Concerning the order of evidence disclosure, respondents tended to suggest that their framing strategy was influenced by their own perception of the strength of the evidence (either presenting what they assessed as the strongest evidence first or last, or the weakest evidence first or last). While this suggests that some forethought may be entered into ahead of interviews, such an approach does rather rely on their assessments of the evidence to hand possessing some validity. Smith and Bull (in press) found investigators had rarely received any training to assist them in making 
such judgments. Further, the public (who, of course, may be suspects at one time or another) were regularly imprecise in calculating correct evidence weight (Smith et al., 2011). As such, respondents' views in the present study (that they gradually disclose evidence either increasingly or decreasingly in regard to its strength) is dependent on both interviewers and suspects possessing similar views as to its weight. It might well be the case that such escalation or de-escalation strategies might not be as effective as respondents think it is due to suspects' misperceptions concerning the value of the disclosed evidence.

The present study is the first to examine in detail investigative practitioners' preference for evidence disclosure strategies and their reasoning behind such choices. It found that there is, among investigative practitioners, a division of opinion as to what is an effective information/evidence disclosure strategy in interviews. Of those who did exercise a choice, a gradual strategy was invariably preferred, with the majority of this particular group opting for what Walsh and Bull ( in press) coined 'deferred gradual' evidence disclosure. For some participants, however, any strategy would need to be adapted case by case to take into account various factors (whether in regard to either timing of framing of evidence disclosure). If this is indeed the case in practice, research that argues for one universal approach may need to be revisited, so that it can be better understand in what circumstances certain approaches are more effective than others in gaining comprehensive accounts from suspects.

While the PEACE training may have influenced such beliefs in a gradual EDM, it remains unknown whether this strategy is actually more efficacious than the other approaches in either obtaining reliable confessions or gaining comprehensive accounts from suspects. Laboratory studies examining EDMs have thus far provided no conclusive approach. Published field studies are rare, although Walsh \& Bull (in 
press) found a 'deferred gradual' approach was both more skilled and more likely to obtain a fulsome account. Nevertheless, more studies (including field ones) are required that involve all the approaches before any solidarity of view as to the most effective EDM is likely to emerge.

\section{References}

Baldwin, J. (1993). Police interview techniques: Establishing truth or proof? British Journal of Criminology, 33, 325-351.

Bull, R. (2013). What is 'believed' or actually 'known' about characteristics that may contribute to being a good/effective interviewer? Investigative Interviewing: Research and Practice, 5, 128-143.

Bull, R. (2014). (Ed.) Investigative interviewing. New York: Springer.

Bull, R., \& Soukara, S. (2010). Four studies of what really happens in police interviews. In G. D. Lassiter, and C. A. Meissner, (Eds.) Police interrogations and false confessions: Current research, practice, and policy recommendations (pp. 8195). Washington: American Psychological Association.

Cassell, P., \& Hayman, B. (1996) Police interrogation in the 1990s: An empirical study of the effects of Miranda. UCLA Law Review, 43, 839-932.

Clarke, C., and Milne, R. (2001). National evaluation of the PEACE investigative interviewing course. Report no: PRAS/149. London: The Home Office.

Dando, C., Bull, R., Ormerod,T., \& Sandham, A. (in press). Helping to sort the liars from the truth-tellers: The gradual revelation of information during investigative interviews. Legal and Criminological Psychology. http://dx.doi.org/10.1111/lcrp.12016.

Dando. C. J., \& Bull, R. (2011). Maximising opportunities to detect verbal deception: Training police officers to interview tactically. Journal of Investigative Psychology and Offender Profiling, 8, 189-202. DOI: 10.1002/jip.145.

DePaulo, B., \& Bond, C. (2012). Beyond accuracy: Bigger, broader ways to think about deceit. Journal of Applied Research in Memory and Cognition, 1, 120121. http://dx.doi.org/10.1016/j.jarmac.2012.04.010.

Fahsing, I. (2014). Can we operationalise the presumption of innocence? He interviewing of suspects in a fair-trial perspective. Paper presented at the $7^{\text {th }}$ International Investigative Interviewing Research group Conference, Switzerland. 
Granhag, P-A., Strömwall, L., Willén, R. \& Hartwig, M. (2012). Eliciting cues to deception by tactical disclosure of evidence: The first test of the Evidence Framing Matrix. Legal and Criminological Psychology, 18, 341-355. DOI: 10.1111/j.20448333.2012.02047.x.

Granhag, P-A., Hartwig, M., Mac Giolla, E., Clemens, F. (2015). Suspects' verbal counter-interrogation: Towards an integrative model. In P-A. Granhag, A. Vrij, \& B. Verschuere (2015) Detecting deception: Current challenges and cognitive approaches (pp. 193-214). Chichester: Wiley.

Granhag, P-A., \& Hartwig, M. (2015). The strategic use of evidence technique: A conceptual overview. In P-A. Granhag, A. Vrij, \& B. Verschuere (2015) Detecting deception: Current challenges and cognitive approaches (pp. 231-251). Chichester: Wiley.

Griffiths A. (2008). An examination into the efficacy of police advanced investigative interview training? Unpublished PhD thesis. University of Portsmouth.

Griffiths, A. \& Milne, R. (2006). Will it all end in tiers? Police interviews with suspects in Britain. In T. Williamson, (Ed.), Investigative interviewing: Rights, research and regulation (pp. 167-189). Cullompton: Willan.

Gudjonsson, G. H., \& Petursson, H. (1991). Custodial interrogation: Why do suspects confess and how does it relate to their crime, attitude and personality? Personality and Individual Differences, 12, 295-306. http://dx.doi.org/10.1016/01918869(91)90116-S.

Gudjonsson, G.H. (2003). The Psychology of Interrogations and Confessions. Chichester: Wiley.

Häkkänen, H., Ask, K., Kebbell, M., Alison, L., \& Granhag, P (2009) Police officers' views of effective interview tactics with suspects: the effects of weight of case evidence and discomfort with ambiguity. Applied Cognitive Psychology, 23, 468-481. http://dx.doi.org/10.1002/acp.1491.

Hartwig, M, Granhag, P.A., Strömwall, L.A. \& Kronkvist, O. (2006). Strategic use of evidence during police interviews: When training to detect deception works. Law and Human Behavior, 30, 603-619. http://dx.doi.org/10.1007/s10979-006-90539.

Hartwig, M., Granhag, P.A., Strömwall, L.A. \& Vrij, A. (2005). Detecting deception via strategic disclosure of evidence. Law and Human Behavior, 29, 469484. DOI: 10.1007/s10979-005-5521-x.

Irving, B. (1980). Police interrogation. A case study of current practice, Research Study No. 2, London: HMSO.

Jordan, S., Hartwig, M., Wallace, B., Dawson, E., \& Xhihani, A. (2012). Early versus late disclosure of evidence: Effects on verbal cues to deception, 
confessions, and lie catchers' accuracy. Journal of Investigative Psychology and Offender Profiling, 9, 1-12. DOI: 10.1002/jip.1350.

Kebbell, M. R., Hurren, E., \& Roberts, S. (2006). Mock-suspects' decisions to confess: The accuracy of eyewitness evidence is critical. Applied Cognitive Psychology, 20, 477-486. http://dx.doi.org/10.1002/acp.1197.

Kebbell, M., Alison, L., Hurren, E., \& Mazerolle, P. (2010). How do sex offenders think the police should interview to elicit confessions from sex offenders? Psychology, Crime and Law, 16, 567-584. http://dx.doi.org/10.1080/10683160902971055.

Leahy- Harland, S. (2012) Police interviewing of serious crime suspects. Unpublished PhD thesis. University of Leicester.

Leo, R. (1996). Inside the interrogation room. Journal of Criminal Law and Criminology, 86, 266-303. http://dx.doi.org/10.2307/1144028.

McDougall, A.J. \& Bull. r. (in press). Detecting truth in suspect interviews: The effect of use of evidence (early and gradual) and time delay on Criteria-Based Content Analysis, Reality Monitoring and inconsistency within suspect statements. Psychology, Crime \& Law, DOI: 10.1080/1068316X.2014.994631

Milne, R., \& Bull, R. (1999). Investigative interviewing: Psychology and practice. Chichester: Wiley.

Moston, S., Stephenson, G. M., \& Williamson, T. (1992). The effects of case characteristics on suspect behaviour during police questioning. British Journal of Criminology, 32, 23-40.

Nystedt, M. Nielsen, C.A.., \& Kleffner, J. K. (Eds.). (2011). A handbook on assisting international criminal investigations. Stockholm: Bernadotte Academy.

O'Neill, M., \& Milne, R. (2014). Succes within criminal investigations: is communication still a key component. In R. Bull, (2014). (Ed.) Investigative interviewing (pp. 123-146. New York: Springer.

Oxburgh, G.E., Ost J.(2011) The Use and Efficacy of Empathy in Police Interviews with Suspects of Sexual Offences. Journal of Investigative Psychology and Offender Profiling, 8, 178-188. http://dx.doi.org/10.1002/jip.143.

Oxburgh, G. E., Williamson, T., \& Ost, J. (2006). Police officers' use of negative emotional language during child sexual abuse investigations. International Journal of Investigative Psychology and Offender Profiling, 3, 35-45.

Read, J., Powell, M., Kebbell, M., \& Milne, R. (2009). Investigative interviewing of sex offenders: A review of what constitutes best practice. International Journal of Police Science and Management, 11, 442- 459. http://dx.doi.org/10.1350/ijps.2009.11.4.143. 
Sellers, S. \& Kebbell, M.R. (2009). When should evidence be disclosed in an interview with a suspect? An experiment with mock-suspects. Journal of Investigative Psychology and Offender Profiling, 6, 151-160. DOI: 10.1002/jip.95.

Shepherd, E, \& Griffiths, A. (2013) Investigative Interviewing: The conversation management approach. Oxford: oxford University Press.

Smith, L.L., \& Bull, R. (in press). Exploring the disclosure of forensic evidence in police interviews with suspects Journal of Police and Criminal Psychology. http://dx.doi.org/10.1350/ijps.2009.11.4.143.

Smith, L.L., Bull, R., \& Holliday, R. (2011). Understanding juror perceptions of forensic evidence: Investigating the impact of case context on perceptions of forensic evidence strength, Journal of Forensic Sciences, 56, 409-414. DOI: 10.1111/j.15564029.2010.01671.x.

Sorochinski, M., Hartwig, M., Osborne, J., Wilkins, E., Marsh J., Kazakov, D., \& Granhag, P.A. (in press). Interviewing to detect deception: When to disclose the evidence? Journal of Police and Criminal Psychology.

http://dx.doi.org/10.1007/s11896-013-9121-2.

Soukara, S., Bull, R., \& Vrij, A. (2002). Police detectives' aims regarding their interviews with suspects. Any change at the turn of the millennium. International Journal of Police Science and Management, 4, 100-114

Soukara, S., Bul, R., and Vrij, A. (2002). Police detectives' aims regarding their interviews with suspects: Any change at the turn of the millennium? International Journal of Police science and Management, 4, 100-114.

Soukara, S., Bull, R., Vrij, A., Turner, M., \& Cherryman, J., (2009). What really happens in police interviews of suspects? Tactics and confessions. Psychology, Crime and Law, 6, 493-506. DOI: 10.1080/10683160802201827.

Tsan-Chang Lin \& Chih-Hung Shih, (2013). A study of police interrogation practice in Taiwan. Paper presented at the Asian Conference of criminal and Police Psychology, Singapore.

van der Sleen, J. (2009). A structured model of investigative interviewing of suspects. In R. Bull, T.Valentine, and T. Williamson (Eds.) Handbook of psychology of investigative interviewing. (pp. 35-52). Chichester: Wiley.

Walsh, D. \& Bull, R. (2010a). Interviewing suspects of fraud: An analysis of interviewing skills. Journal of Psychiatry and Law , 38, 99-135.

Walsh, D. \& Bull, R. (2010b). The interviewing of suspects by non-police agencies: What's effective? What is effective! Legal and Criminological Psychology, 15, 305-321 DOI 10.1348/135532509X463356. 
Walsh, D. \& Bull, R. (2012a) How do interviewers attempt to overcome suspects' denials? Psychiatry, Psychology, and Law, 19, 151-168. http://dx.doi.org/10.1080/13218719.2010.543756.

Walsh, D. \& Bull, R. (2012b). Examining rapport in investigative interviews with suspects: Does its building and maintenance work? Journal of Police and Criminal Psychology, 27, 73-84. DOI 10.1007/s11896-011-9087-x.

Walsh, D., \& Bull, R. ( in press). Interviewing suspects: Examining the association between skills, questioning, evidence disclosure, and interview outcomes, Psychology, Crime and Law.

Walsh, D. \& Milne, R. (2007) Giving PEACE a Chance. Public Administration. 85, 3, 525-540. http://dx.doi.org/10.1111/j.1467-9299.2007.00645.x

Walsh, D. \& Milne, R. (2008). Keeping the P.E.A.C.E.? An Analysis of the taped interview performance of benefit fraud investigators within the DWP. Legal and Criminological Psychology.13, 39-57. DOI: 10.1348/135532506X157179. 


\section{Appendix 1: Survey questionnaire}

This questionnaire concerns evidence disclosure in interviews. It is not related to what you might disclose to lawyers before an interview. Thank you for undertaking this questionnaire. It is part of my research being conducted with my colleagues to examine further what actually practitioners, through their experience, consider as good practice in interviews with suspects. Completion of the questionnaire implies your voluntary consent to take part in this survey. If you, later, wish to withdraw please get in touch with me (my address below). Thanks for taking part in this survey. Your views are so invaluable.

1. Please state your experience as an investigation professional

Less than 1 year $\square \quad 1-3$ years $\square \quad 3-5$ years $\square$

$5-10$ years $\square \quad 10$ years or more $\square$

2. Have you undergone training in the PEACE model of interviewing?

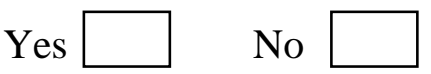

3. Have you undergone any interview training since then (for example advanced interview training?)

Yes $\square$ No $\square$

4. What types of offences do you investigate?

5. Which evidence disclosure mode do you plan to undertake before you undertake the interview ( please ignore issues of pre-interview disclosure to lawyers this question is about your planning for what you will do in the interview itself). Please choose one of the following options

a)Early in the interview - that is before you have gathered an initial account and immediately after you have finished delivering the legal requirements phase

Why.

b) Gradual -in a kind of 'drip feed' effect throughout the interview

Why.

(if gradual when do you plan to begin to gradually disclose that evidence?

Once each part of the account has been fully given

Immediately a contradiction occurs between the account and the evidence to hand

After any denials

At some other point

(if so what is that point?).

c) Late - only once all information gathered and all possible alibis have been given 
Why....

d) Another evidence disclosure mode?

Why....

e) It depends? If it depends, can you state what it depends on? Please choose as many options as you feel appropriate

The suspect's likely willingness to co-operate $\square$

The suspect likely denying the offence? $\square$

The evidence weight that you possess

The amount of evidence (that is, the number of pieces of evidence you possess)

Your assessment of the suspect as likely being guilty

Your assessment of the suspect as being innocent

The offence type

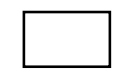

The likely presence of a lawyer

The likely presence of any other third party (friend, social worker, interpreter, appropriate adult etc)?

The complexity of the case?

Any

other

reason?

6. Do you always carry out the planned evidence disclosure strategy? All of the time Most of the time Sometimes Rarely Never

7. If you change the planned strategy what makes you change it?

8. Bearing in mind your answer at Question 5 above, if you change your planned evidence disclosure strategy, do you decide to change.

From early to gradual From early to late

From late to gradual

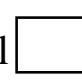

From gradual to early
From late to early

From gradual to late

Any other type of change 
9. If you only ever decide to undertake one disclosure strategy (whichever one it is) why do you not undertake another disclosure mode (e.g. if you have an early disclosure mode why do you not choose either gradual or late).

10. How often do you feel that the suspect is guilty before you start to interview Very often $\square \quad$ Often $\square$ Sometimes $\square \quad$ Rarely $\square$

Why?

11. Does your view affect your strategies regarding evidence disclosure?

Yes No Sometimes

12. In those cases where you have more than one piece of evidence (and regardless of whether you disclose evidence gradually throughout the interview or whether you disclose either at an early, single step or late stage) which order do you disclose the various items of evidence? Please choose just one of the following options.
a) Least strong first
b) Least strong last
c) Most strong first
d) Most strong last
e) What you feel is a logical order
(please state what you mean by a logical order....

f)The one that most obviously contradicts the given account first

g) The one that most obviously contradicts the given account last

h) Chronological order

i) Another order? $\square$ If so what?

j) No particular order

k) It depends. If so, on what and why?

Please state the reasons for your choice of order (regardless of your choice) 
Table 1: Questionnaire response rates: Investigative experience by function of job role

\begin{tabular}{lllll} 
Investigative experience & \multicolumn{3}{c}{ Job role: Percentage within range of experience $(\mathrm{n})$} \\
\hline & Benefit fraud & Volume crime & Other fraud/financial crime & Serious crime \\
Less than one year & -- & -- & $100(6)$ & -- \\
$1-3$ years & $15(2)$ & $50(7)$ & $36(5)$ & -- \\
3-5 years & $33(5)$ & $27(4)$ & $33(5)$ & $7(1)$ \\
$5-10$ years & $27(16)$ & $42(25)$ & $19(11)$ & $12(7)$ \\
10 years plus & $39(51)$ & $24(31)$ & $30(38)$ & $8(10)$ \\
\hline
\end{tabular}

Table 2: Questionnaire response rates: Preferred planned strategy of sample $(\mathrm{n}=221)$

\begin{tabular}{ll}
\hline Planned strategy & $\%$ response $(\mathrm{n})$ \\
\hline Early & $6(14)$ \\
Late & $6(14)$ \\
Gradual & $68(153)$ \\
Context dependent strategy & $12(25)$ \\
'Another' strategy & $7(15)$ \\
\hline
\end{tabular}

Table 3: Questionnaire response rates: Preferred planned strategy by function of job role and investigative experience

Planned strategy

(a)Job role

Benefit fraud investigators

Volume crime police officers

Other fraud investigators

Serious crime police officers

(b) Investigative experience

Less than one year

1-3 years

3-5 years

5-10 years

10 years plus
$\%$ response $(\mathrm{n})$ within $(\mathrm{a})$ job role, and (b) investigative experience

$\begin{array}{lllcl}\text { Early } & \text { Late } & \text { Gradual } & \text { Context dependent } & \text { other } \\ 3(2) & 1(1) & 73(53) & 15(11) & 8(6) \\ 13(9) & 15(10) & 61(41) & 6(4) & 5(3) \\ 5(3) & 5(3) & 70(44) & 11(7) & 10(6) \\ 6(1) & -- & 78(14) & 17(3) & -- \\ & & & & \\ -- & 25(1) & 75(3) & -- & -- \\ 7(1) & 7(1) & 50(7) & 14(2) & 21(3) \\ 7(1) & 13(2) & 60(9) & 7(1) & 13(2) \\ 5(3) & 7(4) & 73(43) & 12(7) & 2(4) \\ 8(10) & 5(6) & 68(90) & 12(15) & 7(6)\end{array}$


Table 4: Questionnaire response rates: Planned framing of pieces of evidence

\% response $(n)$

Entire sample regardless of EDM $(n=199)$

Least strong presented first

Strongest piece of evidence last $\quad 7$ (13)

Strongest piece evidence last 7 (14)

Chronological incidence 16(32)

Logical order 2 (4)

Contextual dependency $13(25)$

No plan $21(42)$

Respondents who opted for a gradual EDM $(n=149)$

Least strong presented first 38(56)

Strongest piece of evidence last $\quad 8(12)$

Strongest piece evidence last $\quad 9(13)$

Chronological incidence 16(24)

Logical order 2 (3)

Contextual dependency $11(16)$

No plan $17(25)$

Table 5: Questionnaire response rates: Frequency of guilt presumption

$\%$ response of sample responding to question $(n=216)$

By function of professional; experience

Less than 1 year $1-3$ years $3-5$ years $5-10$ years 10 years or more

Guilt presumed very often

Guilt presumed often

$\begin{array}{ll}- & 1(3) \\ 2(4) & 3(7) \\ 1(1) & 1(3) \\ & 1(1)\end{array}$

$\begin{array}{ll}- & 5(11) \\ 2(4) & 9(20)\end{array}$

$9(20)$

Guilt presumed sometimes

Guilt presumed rarely or never

$1(1)$

4(9) $9(20)$

24(51)

1(1) 3(7)

$21(46)$

$4(8)$

By function of job role

Guilt presumed very often

Guilt presumed often

Guilt presumed sometimes

Guilt presumed rarely or never

Benefit fraud Financial crime Volume crime Serious crime

3(6) 7(14)

13(27) 11(24)

15(33) $9(20)$

2(5) 1(3)
$1(1)$

15(33) $\quad 1(2)$

$7(15) \quad 5(11)$

2(5) 2(4) 
Table 6: Results of multiple regression analysis: Predictor variable of the RESPONDENTENTS' chosen EDM

\section{$b \quad S E b \quad \beta$}

\begin{tabular}{llll}
\hline & & & \\
PEACE trained & 1.71 & 0.26 & 0.01 \\
Received advanced training & 7.41 & 0.16 & 0.40 \\
Investigative job role & 0.19 & 0.07 & $0.20^{*}$ \\
Investigative experience & 3.74 & 0.08 & 0.03 \\
Presumption of guilt & 5.56 & 0.01 & 0.04 \\
\hline
\end{tabular}

Note: $R=0.22 ; R$ square $=0.05 ;$ adjusted $R$ square $=0.02 .{ }^{*} p=<0.01$ 